\title{
O JULGAMENTO DO CASO DA FOSFOETANOLAMINA E A JURISPRUDÊNCIA DO SUPREMO TRIBUNAL FEDERAL
}

The judgment on the phosphoethanolamine case and the jurisprudence of the Brazilian Federal Supreme Court

${ }^{1}$ Universidade Federal do Rio de Janeiro. Rio de Janeiro/RJ, Brasil.

Correspondência: José Carlos Zebulum. E-mail: jcarloszebulum@gmail.com.

Recebido em: 20/12/2015. Revisão: 24/03/2016. Aprovado: 28/03/2016. 


\section{RESUMO}

Recentemente noticiou-se a difusão do uso da substância fosfoetanolamina sintética, conhecida como a pílula do câncer, entre portadores de neoplasia maligna. Ocorre que a substância, além de não contar com registro na Agência Nacional de Vigilância Sanitária, sequer havia concluído os estudos clínicos necessários à garantia de sua eficácia e segurança. Não obstante, o governo federal editou a Lei n. 13.269/2016, que autorizava o fornecimento pelo Sistema Único de Saúde sob determinadas condições, e diversas liminares foram concedidas obrigando o Estado a fornecê-la. A questão foi apreciada pelo Supremo Tribunal Federal em dois rumorosos julgamentos, em que a Corte suspendeu todas as liminares concedidas e suspendeu a eficácia da referida lei por indícios de inconstitucionalidade. Neste artigo analisamos os fundamentos das citadas decisões no contexto de posicionamentos anteriores da Corte e das orientações estabelecidas no julgamento do Agravo Regimental na Suspensão de Tutela Antecipada 175.

\section{Palavras-Chave:}

Direito à Saúde; Fosfoetanolamina; Judicialização; Jurisprudência.

\section{ABSTRACT}

Widespread use of the synthetic substance phosphoethanolamine, known as the cancer pill, was recently reported among patients with malignant neoplasm. However, the substance was not registered in the Brazilian National Health Surveillance Agency and the clinical studies necessary to guarantee its effectiveness and safety had not even been completed. Nevertheless, the federal government enacted Law number 13.269/2016, authorizing provision by the Brazilian National Public Health System under certain conditions, and various injunctions were granted that forced the state to provide it. The question was considered by the Supreme Court in two important judgments in which the Court suspended all injunctions granted and suspended the effectiveness of the law based on evidence of unconstitutionality. In this article, we analyze the legal grounds of the decisions in the context of previous positions of the Court and the guidelines established in judgment of STA 175-AgR/CE.

\section{Keywords:}

Judicialization; Jurisprudence; Phosphoetanolamine; Right to Health. 


\section{Introdução}

Os medicamentos constituem-se de tecnologias terapêuticas que se submetem a reiteradas pesquisas antes e depois de seu registro e comercialização. A avaliação de medicamentos é um processo que ocorre desde seu desenvolvimento, por meio de testes de toxicidade, eficácia e segurança, até seu uso na prática clínica, quando se torna possível conhecer os reais benefícios e os potenciais danos que podem causar na população. No Brasil, a Agência Nacional de Vigilância Sanitária (Anvisa), criada pela Lei n. 9.782/99 ${ }^{1}$, é o órgão regulador responsável pela autorização para que se inicie uma pesquisa com medicamentos com o objetivo de se adquirir ou mesmo renovar um registro, após aprovação quanto aos critérios éticos adotados ${ }^{2}$.

O desenvolvimento de um novo fármaco - molécula ou substância ativa responsável pelo efeito terapêutico de um medicamento - inicia-se com a descoberta do fármaco e pode ser dividido em três etapas assim discriminadas: (a) descoberta de um composto com atividade terapêutica; (a) estudos pré-clínicos e (c) estudos clínicos. Os estudos pré-clínicos têm o objetivo principal de avaliação farmacológica em sistemas in vitro e em animais in vivo para a obtenção do maior conhecimento possível acerca de suas propriedades e de seus efeitos adversos ${ }^{3}$. Além disso, o composto é submetido a testes de toxicidade em animais para que suas propriedades farmacológicas possam ser definidas dentro de uma relação dose-resposta ${ }^{4}$.

\footnotetext{
${ }^{1}$ BRASIL. Lei n. 9.782, de 26 de janeiro de 1999. Define o Sistema Nacional de Vigilância Sanitária, cria a Agência Nacional de Vigilância Sanitária, e dá outras providências. Disponível em: < http://www.planalto. gov.br/ccivil_03/leis/L9782.htm>. Acesso em: 16 ago. 2016.

${ }^{2}$ FREITAS, Letícia Figueira. Pesquisas envolvendo medicamentos na região Sudeste, Brasil: uma análise exploratória na base de dados do Sistema de Avaliação Ética de Pesquisas. 118f. 2011. Dissertação (Mestrado em Saúde Pública). Escola Nacional de Saúde Pública Sergio Arouca, Rio de Janeiro, 2011.

${ }^{3}$ FERREIRA, Filipe Galvão et al. Fármacos: do desenvolvimento à retirada do mercado. Rev. Eletrônica de Farmácia, v. 6, n. 1, p. 14-24, 2009. Disponível em: <https://www.revistas.ufg.br/REF/article/download/5857/4557>. Acesso em: 31 jan. 2017.

${ }^{4}$ Os ensaios clínicos compreendem a realização de estudos controlados e randomizados, em indivíduos voluntários, com vistas à demonstração de evidências sobre a eficácia e a segurança de determinada intervenção terapêutica, seja para um novo medicamento, seja para uma nova forma de se utilizar um medicamento já conhecido e consagrado. São estudos de custo bastante elevado e que são realizados em três fases: na primeira fase dá-se a administração do composto em humanos (30-100 voluntários) e deve seguir os preceitos éticos internacionais. Nessa fase utilizam-se normalmente voluntários sadios e, eventualmente, os testes podem ser realizados em pacientes gravemente enfermos em circunstâncias nas quais a toxicidade elevada torna-se aceitável, como no caso de pacientes com câncer, por exemplo (FERREIRA, Filipe Galvão et al. op. cit., p. 14-24). 0 objetivo principal dessa fase é avaliar a tolerância em seres humanos e determinar a posologia segura (LIMA, Janderson et al. Pesquisa clínica: fundamentos, aspectos éticos e perspectivas. Revista da Socerj, v.16, n.4, p.225-233, 2003. Disponível em: <http://www.rbconline.org.br/artigo/pesquisa-clinica-fundamentos-aspectos-eticos-e-perspectivas/>. Acesso em: 31 jan. 2017.), coletando-se, também, os dados de segurança do medicamento. Já na terceira fase, tanto se aumenta a amostragem como se diversifica a gama de pessoas nos testes. Nessa fase, também são incluídos tratamentos mais prolongados com o composto, cerca de seis a 12 meses, visando à flexibilidade na dosagem, bem como a coleta de dados sobre segurança e eficácia do mesmo (PIMENTEL, Luis Cláudio Ferreira et al. O inacreditável emprego de produtos químicos perigosos no passado. Química Nova, v. 29, n. 5, p. 1138-1149, 2006). A partir da edição da Lei n. 12.401/2011, que criou a Comissão Nacional de Incorporação de Tecnologias no SUS (Conitec), a incorporação, pelo SUS, de nova medicação ao seu elenco de medicamentos a serem fornecidos para tratamento de patologias deverá ser feita após manifestação favorável do órgão, cujo relatório levará em consideração, necessariamente, as evidências científicas sobre a eficácia, a efetividade e a segurança do medicamento, além de uma avaliação econômica comparativa dos benefícios e dos custos em relação às tecnologias já incorporadas.
} 
No caso da fosfoetanolamina sintética (pílula do câncer), a edição da Lei n. 13.269/2016 $6^{5}$ que autorizava o uso da substância por pacientes diagnosticados com neoplasia maligna, desconsiderou todas as ferramentas científicas acima citadas, exigidas no interesse da comprovação da qualidade, segurança e eficácia dos medicamentos. Afrontou, igualmente, o sistema regulatório de saúde nacional ao rechaçar a legislação já consolidada que versa sobre vigilância sanitária e registro de medicamento ${ }^{6}$. A substância começou a ser sintetizada por um pesquisador do Instituto de Química de São Carlos (IQSC-USP) no final da década de 1980 e, mesmo sem ter sido submetida às etapas de pesquisa necessárias para o desenvolvimento de um medicamento - e, portanto, enquanto ainda não havia qualquer evidência científica de que o produto seria seguro para o consumo humano -, começou a ser fornecida a pacientes informalmente ${ }^{7}$.

Neste artigo, nosso objetivo é verificar se as duas recentes decisões proferidas no âmbito do Supremo Tribunal Federal (STF) - a primeira, nos autos da Suspensão de Tutela Antecipada 828/SP ${ }^{8}$ (STA 828/SP); a segunda, nos autos da Ação Direta de Inconstitucionalidade 5.501/ $\mathrm{DF}^{9}$ (Adin 5.501/DF); ambas referentes ao caso da fosfoetanolamina sintética - seguem, efetivamente, a jurisprudência da Corte. Para tanto, antes de abordarmos os fundamentos das decisões propriamente ditas, iremos descrever, de forma sucinta, o balizamento estabelecido pelo STF a respeito do tema, mormente a partir da realização da audiência pública de 2009, em que o Supremo Tribunal Federal avocou para si a discussão da problemática envolvida no fenômeno da judicialização da saúde.

${ }^{5}$ BRASIL. Lei n. 13.269, de 13 de abril de 2016. Autoriza o uso da fosfoetanolamina sintética por pacientes diagnosticados com neoplasia maligna. Disponível em: < http://www.planalto.gov.br/ccivil_03/_Ato20152018/2016/Lei/L13269.htm>. Acesso em: 16 ago. 2016.

${ }^{6}$ ALVES, Sandra Mara Campos; DELDUQUE, Maria Célia; SANTOS, Alethele Oliveira. Lei n 13.269/2016: a comoção da sociedade vence o método científico! Cad. Saúde Pública, Rio de Janeiro, v. 32, n. 6, jun. 2016. Disponível em: <http://www.scielo.br/pdf/csp/v32n6/1678-4464-csp-32-06-e00070116.pdf>. Acesso em: 31 jan. 2017.

'LENHARO, Mariana. 'Cápsula da USP' contra câncer não foi testada clinicamente; entenda, 2015. Disponível em: <http://g1.globo.com/ciencia-e-saude/noticia/2015/09/pilula-da-usp-contra-cancernao-passou-por-testes-clinicos-entenda.html>. Acesso em: 13 jul. 2016. Em junho de 2014, uma portaria do IQSC reforçou a proibição federal a respeito da produção e distribuição, por pesquisadores da universidade, de substâncias não aprovadas como medicamento pela Anvisa. Embora o ato administrativo não mencionasse expressamente a fosfoetanolamina, este era seu alvo. Assim, os pacientes que já vinham recebendo a fosfoetanolamina de modo informal, e outros tantos que, ao tomarem conhecimento, também reivindicavam o fornecimento da droga, conseguiram liminares na Justiça e obtiveram, assim, o direito de continuar a receber da USP as pílulas do composto. PIVETA, Marcos. A prova final da fosfoetanolamina, 2016. Revista Pesquisa FAPESP, ed. 243, maio 2016. Disponível em: <http://revistapesquisa.fapesp.br/2016/05/17/a-prova-final-da-fosfoetanolamina/>. Acesso em:13 jul. 2016.

${ }^{8}$ SUPREMO TRIBUNAL FEDERAL. Suspensão de Tutela Antecipada n. 828/SP. Disponível em: <http://www. stf.jus.br/portal/processo/verProcessoAndamento.asp? numero $=828 \&$ classe $=$ STA\&origem $=A P \&$ recurso $=0$ \&tipoJulgamento=M>. Acesso em: 31 jan. 2017.

${ }^{9}$ SUPREMO TRIBUNAL FEDERAL. Ação Direta de Inconstitucionalidade n. 5.501/DF. Disponível em: <http:// www.stf.jus.br/arquivo/cms/noticiaNoticiaStf/anexo/MS34145.pdf>. Acesso em: 31 jan. 2017. 


\section{0 balizamento estabelecido pelo Supremo Tribunal Federal}

Os debates promovidos pela audiência pública de 2009 e a própria prática anterior da Corte levaram o STF, em um julgado emblemático, à fixação de parâmetros para o tema da judicialização da saúde. Trata-se do julgamento do Agravo Regimental na Suspensão de Tutela Antecipada n. 175/CE ${ }^{10}$ (STA 175-AgR/CE), que tem sua origem na ação judicial proposta por um paciente portador de uma raríssima doença (doença de Niemann-Pick Tipo C) contra a União, o Estado do Ceará e o Município de Fortaleza, em que se pugnava pela condenação solidária dos entes públicos ao fornecimento do medicamento Zavesca, não registrado na Anvisa e cujo custo mensal estava estimado em cerca de 52 mil reais ${ }^{11}$.

O Gilmar Mendes, relator do STA 175-AgR/CE, em seu voto - que foi ratificado à unanimidade pelo plenário do STF -, analisa diversas questões envolvidas na concretização do direito fundamental à saúde, estabelecendo importantes diretrizes a serem observadas no julgamento de demandas por medicamentos e serviços de saúde. Tais diretrizes podem ser assim sintetizadas:

(a) Na maioria dos casos em que o Judiciário é demandado para decidir questões de saúde, a intervenção judicial não ocorre em razão da inexistência de políticas públicas voltadas à proteção do direito à saúde, mas em virtude de políticas já estabelecidas e ignoradas por parte da Administração ${ }^{12}$.

(b) Os juízes, salvo em casos excepcionais, não devem condenar o Estado ao fornecimento de prestação de saúde não registrada na Anvisa, eis que o registro, além de garantir a segurança e o benefício do medicamento, é fator preponderante em sua regulação econômica. Pelo mesmo motivo, também não devem impor ao poder público a obrigação de fornecer medicamento que ainda esteja em fase experimental.

(c) Em princípio, os medicamentos devem ser dispensados para os pacientes que se enquadrarem nos critérios estabelecidos nos respectivos protocolos clínicos

\footnotetext{
${ }^{10}$ SUPREMO TRIBUNAL FEDERAL. Agravo Regimental na Suspensão de Tutela Antecipada n. 175/CE. Disponivel em: <http://redir.stf.jus.br/paginadorpub/paginador.jsp?docTP=AC\&doclD=610255>. Acesso em: 31 jan. 2017.

${ }^{11}$ BALESTRA NETO, Otávio. A jurisprudência dos tribunais Superiores e o direito à saúde. Evolução rumo à racionalidade. R. Dir. Sanit., São Paulo v.16 n.1, p. 87-111, mar./jun. 2015. Disponível em: <http://www. revistas.usp.br/rdisan/article/view/100025>. http://dx.doi.org/10.11606/issn.2316-9044.v16i1p87-111. 0 Tribunal Regional Federal da $5^{\text {a }}$ Região concedeu a tutela, determinando o imediato fornecimento, mas a União requereu suspensão da tutela antecipada à Presidência do STF. Diante da decisão monocrática do então Presidente da Corte, Gilmar Mendes, que manteve a decisão do Tribunal Regional Federal da $5^{\text {a }}$ Região, houve interposição de agravo regimental que provocou a manifestação do plenário do STF.

${ }^{12}$ SUPREMO TRIBUNAL FEDERAL. Agravo Regimental na Suspensão de Tutela Antecipada n. 175/CE, cit. Portanto, via de regra, não se cogita de indevida interferência judicial na formulação de políticas públicas, mas sim de simples controle de legalidade do exercicio da função administrativa. Partindo-se dessa premissa, o primeiro dado a ser considerado pelo juiz, ao examinar a pretensão do demandante a um determinado bem ou serviço na área da saúde, é a existência, ou não, de política estatal que abranja a prestação pleiteada pela parte, uma vez que, em caso positivo, ao deferi-la o Poder Judiciário não está criando política pública, mas apenas determinando o seu cumprimento (destaques do autor).
} 
e diretrizes terapêuticas (PCDT) do SUS. Confere-se, entretanto, ao Poder Judiciário a possibilidade de decidir que alternativa diferente daquela indicada e custeada pelo SUS deve ser adotada, desde que se comprove que o tratamento fornecido não é eficaz no caso particular de determinada pessoa.

(d) Constatada omissão ou demora excessiva por parte do SUS no desempenho da obrigação de rever, periodicamente, os protocolos existentes e, se for caso, elaborar novos protocolos para se adequar a uma nova realidade, caberá ao prejudicado recorrer ao Poder Judiciário.

Em resumo, é possível identificar uma orientação de caráter geral do STF para as ações voltadas à tutela do direito à saúde, qual seja, a de que

a situação clínica individual do paciente, com base em laudo médico, pode impor obrigações ao Estado, limitando ou até mesmo negando a validade e legitimidade da regulamentação administrativa concernente à assistência terapêutica no SUS ${ }^{13}$.

Tal orientação, no entanto, é relativizada, em virtude dos seguintes posicionamentos que vêm sendo assumidos no âmbito da Corte $^{14}$ :

(a) Quando, para fornecimento de medicamentos não listados pelas portarias do SUS, o STF exige a demonstração de que estes se revelem mais adequados ao tratamento do reivindicante do que aqueles eventualmente disponibilizados pelo SUS ${ }^{15}$.

(b) Quando o STF condiciona o deferimento de medicamentos ou serviços de saúde à disponibilidade financeira do ente público a fim de evitar o comprometimento do funcionamento do SUS, com prejuízo para a coletividade ${ }^{16}$.

\footnotetext{
${ }^{13}$ VENTURA, Miriam. O processo decisório judicial e a assessoria técnica: a argumentação jurídica e médicosanitária na garantia do direito à assistência terapêutica no SUS.186f. 2012. Tese (Doutorado em Saúde Pública). Escola Nacional de Saúde Pública Sergio Arouca, Rio de Janeiro, 2012. p. 23.

${ }^{14}$ Como será visto mais adiante, o plenário do STF irá relativizar novamente essa orientação ao concluir o julgamento do caso da fosfoetanolamina sintética.

${ }^{15}$ Essa orientação consta do voto de Gilmar Mendes no julgamento do STA 175-AgR/CE, como se verifica da diretriz (c) referida. Tal entendimento foi reiterado nos seguintes julgados: STF, STA424/SC, Rel. Min. GILMAR MENDES (Presidente), j. 20/04/2010, DJe 29/04/2010; STF, STA260/SC, Rel. Min. GILMAR MENDES (Presidente), j. 20/04/2010, DJe 07/05/2010; STF, STA434/BA, Rel. Min. GILMAR MENDES (Presidente), j. 16/04/2010, DJe 23/04/2010; e STF, STA283/PR, Rel. Min. GILMAR MENDES (Presidente), j. 07/04/2010, DJe 14/04/2010.

${ }^{16} \mathrm{Em}$ decisão proferida no julgamento da Arguição de Descumprimento de Preceito Fundamental 45/DF (ADPF 45/DF) , Celso de Mello já advertia que o encargo governamental de tornar efetiva a aplicação dos direitos econômicos, sociais e culturais estaria condicionado à cumulação dos seguintes fatores: razoabilidade da pretensão e disponibilidade financeira do Estado. Na hipótese de ausência de qualquer um desses elementos, restaria descaracterizada a possibilidade estatal de realização prática de tais direitos. (ADPF-MC 45, Rel. Celso de Mello, DJ 4.5.2004). Mais tarde, a Ellen Gracie, no julgamento da Suspensão de Segurança 3073/RN, em decisão monocrática proferida em 2007, ocasião em que presidia a Corte, ratificaria esta orientação.
} 
(c) Quando o STF exige, inclusive com base na legislação pátria acima referida, que o medicamento/tratamento requerido deve estar aprovado nas instâncias sanitárias brasileiras e, excepcionalmente, nos países de origem, quando for necessária importação ${ }^{17}$.

(d) Quando o STF mantém liminares deferidas em instâncias inferiores de concessão de medicamentos ou tratamentos, com base na existência do chamado periculum in mora inverso. Trata-se de casos em que se admite o custeio de medicamentos pelo Estado, ainda que sem registro na Anvisa, ante a imprescindibilidade do fornecimento de medicamento para melhora da saúde e manutenção da vida do paciente ${ }^{18}$.

\section{0 julgamento do caso da fosfoetanolamina sintética}

Uma vez que a Universidade de São Paulo(USP) suspendeu a produção e distribuição da fosfoetanolamina - a pílula do câncer -, diversas pessoas que já vinham recebendo a substância de modo informal recorreram à Justiça pelo direito de continuar a receber da USP as pílulas do composto. Diante de um enorme volume de liminares, e sem condições de cumpri-las, a Universidade de São Paulo ingressou no Supremo Tribunal Federal com o pedido de suspensão de tutela antecipada, que foi autuado sob o número $828 / \mathrm{SP}^{19}$.

Após parecer favorável à suspensão da tutela pela Procuradoria Geral da República, o então Presidente da Corte, Ricardo Lewandowski, em decisão monocrática, deferiu em parte o pedido e suspendeu todas as decisões judiciais proferidas em âmbito nacional que houvessem determinado à USP o fornecimento da substância fosfoetanolamina sintética para tratamento de câncer, mantendo seu fornecimento apenas enquanto houvesse estoque do referido composto na Universidade, observada a primazia dos pedidos mais antigos.

\footnotetext{
${ }^{17} \mathrm{Há}$, de fato, entendimento consolidado da Corte no sentido de admitir o custeio pelo Estado de medicamento não registrado pela Anvisa, desde que a eficácia do fármaco esteja atestada e aprovada por entidade governamental congênere à agência. Os seguintes julgados são ilustrativos: STF, SL 815 AgR / SP, Tribunal Pleno, Rel. Min. RICARDO LEWANDOWSKI (Presidente), j. 07/05/2015, DJe 03/06/2015 e STF, SL 887 AgR/CE, Tribunal Pleno, Rel. Min. RICARDO LEWANDOWSKI (Presidente), j. 07/10/2015, DJe 23/10/2015.

${ }^{18}$ Essa orientação foi adotada nos seguintes julgados: STF, STA761 AgR/DF, Tribunal Pleno, Rel. Min. RICARDO LEWANDOWSKI (Presidente), j. 07/05/2015, DJe 28/05/2015; STF, SL47 AgR/PE, Tribunal Pleno, Rel. Min. GILMAR MENDES (Presidente), j. 17/03/2010, DJe 29/04/2010; STF, SS2944/PB,Rel. Min. ELLEN GRACIE (Presidente), j. 17/08/2006, DJ 24/08/2006, p. 0020; e STF, SS4739 AgR/CE, Tribunal Pleno, Rel. Min. RICARDO LEWANDOWSKI (Presidente), j. 07/10/2015, DJe 23/10/2015.

${ }^{19} \mathrm{Em}$ síntese, a USP argumentou que: (a) Os estudos científicos relativos às propriedades anticancerígenas da substância foram interrompidos nos estágios iniciais da pesquisa, sendo impossível sustentar sua eficácia; (b) não haveria como se afastar a possibilidade de seu consumo provocar prejuízos ao organismo das pessoas, haja vista que também não foram realizados estudos sobre sua toxidade; (c) a Universidade foi criada para prestar serviço público de educação superior, não havendo pertinência entre suas finalidades institucionais e a prestação de serviço público de saúde, como o fornecimento de medicamentos, sendo esta uma responsabilidade da Secretaria de Estado da Saúde de São Paulo; e (d) o fornecimento da fosfoetanolamina sintética por parte da Universidade de São Paulo, enquanto objeto de pretensão jurisdicional, passaria ao largo da jurisprudência do Supremo Tribunal Federal, que se tem dedicado a medicamentos às vezes caros demais para que o cidadão os alcance, às vezes não registrados na Anvisa, mas registrados em instâncias internacionais, às vezes detentores de indicações clínicas alegadamente insuficientes para abarcar novas aplicações pretendidas por novos pacientes. SUPREMO TRIBUNAL FEDERAL. Suspensão de Tutela Antecipada n. 828/SP, cit.
} 
Em sua fundamentação, Lewandowski ressaltou o entendimento que vem prevalecendo na Corte, no sentido de que, em se tratando de medicamento não registrado pela Anvisa, mas de uso aprovado por entidade congênere à agência reguladora nacional, quando há comprovação de ser "o único eficaz para debelar determinada enfermidade que coloca em risco a vida de paciente sem condições financeiras", o Estado tem a obrigação de custear o tratamento. Com base neste e em outros argumentos, suspendeu todas as decisões judiciais que houvessem determinado o fornecimento da substância fosfoetanolamina sintética ${ }^{20}$.

Pouco mais de um mês após a decisão de Lewandowski, foi a vez de o plenário da Corte se debruçar sobre o tema, eis que chegara o momento de apreciar, em caráter liminar, a Adin 5.501/DF, interposta pela Associação Médica Brasileira, em face da Lei n. 13.269/2016 $6^{21}$ - que autorizava, sob determinadas condições, o uso da fosfoetanolamina sintética por pacientes diagnosticados com neoplasia maligna ${ }^{22}$.

Marco Aurélio Mello, relator, em seu voto pela suspensão da eficácia da Lei n. 13.269/2016, argumentou que a inexistência de registro na Anvisa torna presumida a inadequação do produto; que houve ofensa ao postulado da separação de poderes, eis que a competência de autorizar a distribuição de substâncias químicas foi descentralizada e outorgada à Anvisa; e que somente a Agência Reguladora dispõe de aparato técnico especializado para realizar o controle dos medicamentos fornecidos à população; salientou, por fim, os graves riscos advindos da manutenção da eficácia da lei impugnada ${ }^{23}$.

\footnotetext{
${ }^{20}$ Lewandowski observou também que o caso da fosfoetanolamina sintética em nada se assemelhava àqueles já examinados pela Corte, caracterizando-se como uma situação nova por se tratar de uma substância química que ainda não teve o seu ciclo de estudos concluído, de um medicamento não registrado na Anvisa nem em entidade congênere, sem que já houvesse sido submetido a testes ou a estudos hábeis a aprovar a sua distribuição e comercialização. Observe-se, por oportuno, que a decisão monocrática do Ministro Presidente se alinha, perfeitamente, à jurisprudência da Corte, uma vez que seus fundamentos se harmonizam com os balizamentos estabelecidos pelo Tribunal com base no voto de Gilmar Mendes no julgamento da STA 175 AgR/CE, acima abordados. SUPREMO TRIBUNAL FEDERAL. Suspensão de Tutela Antecipada n. 828/SP, cit. ${ }^{21}$ BRASIL. Lei n. 13.269, de 13 de abril de 2016, cit.

${ }^{22} \mathrm{Os}$ argumentos trazidos pela Associação Médica Brasileira são muito parecidos com aqueles que já haviam sido introduzidos pela USP na ação anterior, sendo desnecessário repeti-los. Convém, aqui, destacar apenas alguns dos argumentos suscitados pela Presidência da República, pelo Senado Federal e pela Câmara de Deputados em defesa da lei: (a) o Congresso Nacional deflagrou o processo legislativo sensibilizado pelo anseio de cura dos pacientes e familiares, tendo em conta notícias da eficácia do medicamento; (b) a fosfoetanolamina não consiste em produto químico artificialmente criado, mas sim em substância normalmente produzida pelo organismo humano, com funções metabólicas conhecidas pela ciência, daí decorrendo sua baixa toxicidade; (c) com o advento da lei, a droga em questão se tornaria disponível à população apenas quando produzida em laboratórios devidamente credenciados, o que acabaria por estancar o mercado clandestino que já havia sido criado na esteira da busca pelo medicamento por milhares de pacientes. STF suspende eficácia da lei que autoriza uso da fosfoetanolamina. Portal do STF, 19 maio 2016. Disponível em: <http://www.stf.jus.br/portal/ cms/verNoticiaDetalhe.asp?idConteudo=317011\&caixaBusca=N>. Acesso em: 13 jul. 2016.

${ }^{23}$ Votaram com o relator Luís Roberto Barroso e Teori Zavascki, estes enfatizando a interferência indevida do Poder Legislativo em questão técnica, típica do Poder Executivo; Luiz Fux, sufragando a tese do perigo inverso, uma vez que seria possível aferir, com exatidão, as possíveis consequências maléficas do uso dessa substância; Cármen Lúcia, observando que a suspensão da eficácia da lei seria necessária para que "não se veja na pílula do câncer mais uma pílula de engano para quem já está sofrendo com o desengano"; e Lewandowski, destacando que seria inadmissível que o Estado - sobretudo no campo da saúde, que diz respeito à vida e à dignidade da pessoa - possa agir irracionalmente, levando em conta razões de ordem metafísica, ou fundado em suposições que não tenham base em evidências científicas. STF suspende eficacia da lei que autoriza uso da fosfoetanolamina, cit.
} 
Edson Fachin divergiu do relator com base em dois fundamentos: (a) a lei em questão seria perfeitamente aplicável em casos em que já não houvesse outras opções eficazes para garantir a pacientes terminais um mínimo de qualidade de vida; e (b) a Anvisa não detém competência privativa para autorizar a comercialização de toda e qualquer substância, sendo perfeitamente admissível que o Congresso autorize a produção e o fornecimento, dispensando-se o registro em situações excepcionais ${ }^{24}$.

Rosa Weber acompanhou a divergência com base em fundamento semelhante ao primeiro apresentado por Edson Fachin. Dias Toffoli também divergiu do relator e votou pela possibilidade de permitir aos pacientes terminais o acesso ao medicamento. Argumentou que o Poder Judiciário não tem competência para avaliar se um medicamento é seguro ou eficaz, sob pena de invadir atribuição que seria da Anvisa. Gilmar Mendes também divergiu do relator, e o fez com base em dois argumentos: (a) não há violação à prerrogativa do Executivo para dispor sobre tal matéria, uma vez que toda a legislação que hoje disciplina o SUS poderia ser alterada por ato do legislador ordinário, inclusive no que diz respeito a quem caberia a iniciativa da lei; e (b) o Supremo, ao suspender a eficácia da norma questionada, estará estimulando a judicialização da questão ${ }^{25}$.

Ao analisarmos os votos vencedores, verificamos que dois fundamentos prevalecem: a preocupação com as possíveis consequências maléficas do uso da substância, ea interferência indevida do Poder Legislativo em questão técnica, que seria típica do Poder Executivo. De outro lado, aqueles que divergiram do relator se apoiaram no argumento de que a lei em questão não afrontaria a Constituição Federal de 1988 (CF/88), desde que aplicada a pacientes terminais, casos em que já não haveria outras opções eficazes.

Dentre todos os votos analisados, nos chama a atenção, porém, o voto Gilmar Mendes, em sentido contrário à suspensão da eficácia da Lei n. 13.269/2016 - e anuindo, portanto, com a distribuição de substância química à população enquanto ainda não havia qualquer evidência científica de que o produto, sem registro na Anvisa, seria seguro para o consumo humano. Importante recordar que o Ministro, por ocasião do julgamento do STA $175 \mathrm{AgR/CE}$, manifestara-se no sentido de que apenas em casos excepcionais o Poder Judiciário poderia determinar o fornecimento de fármaco desprovido de registro na agência reguladora ${ }^{26}$. Note-se que Mendes, naquele mesmo julgamento, salientara a impossibilidade de se obrigar o SUS a custear medicamentos que ainda se encontrassem em fase experimental ${ }^{27}$. Ora, a fosfoetanolamina sequer poderia ser caracterizada como um medicamento, ante a inexistência de pesquisas conclusivas sobre sua toxidade, eficácia e segurança.

\footnotetext{
${ }^{24}$ STF suspende eficacia da lei que autoriza uso da fosfoetanolamina, cit.

${ }^{25}$ Id. Ibid.

${ }^{26}$ Gilmar Mendes admitira tal possibilidade apenas no caso de medicamentos adquiridos por intermédio de organismos multilaterais internacionais, para uso em programas de saúde pública pelo Ministério da Saúde, desde que comprovado que os medicamentos já estivessem registrados no país de origem. SUPREMO TRIBUNAL FEDERAL. Agravo Regimental na Suspensão de Tutela Antecipada n. 175/CE, cit.

${ }^{27}$ Id. Ibid.
} 


\section{Considerações Finais}

A decisão do Supremo Tribunal Federal, ao acatar o pedido de suspensão da eficácia da Lei n. 13.269/2016 por indícios de inconstitucionalidade, não significa, absolutamente, uma ruptura com seu entendimento tradicional. Com efeito, é possível verificar, na jurisprudência da Corte, a determinação de fornecimento por ente público de medicamentos, às vezes caros demais para o cidadão comum, às vezes não registrados na Anvisa, mas registrados em instâncias internacionais, ou mesmo sem qualquer registro, desde que comprovada a ineficácia ou a impropriedade do medicamente constante de lista ou protocolo ${ }^{28}$. Ocorre que a questão ora posta à apreciação do Tribunal não se enquadra em nenhuma dessas situações, caracterizando-se como uma situação verdadeiramente nova por se tratar de uma substância química que sequer teve seu ciclo de estudos concluído. Trata-se de medicamento (se é que assim pode ser considerado) que, além de não estar registrado na Anvisa, nem em outra entidade congênere, não foi submetido a testes ou a estudos hábeis para aprovar e conferir segurança à sua distribuição e comercialização ${ }^{29}$.

Não obstante, apesar da novidade que o julgamento do caso da fosfoetanolamina sintética sugere, é possível estabelecer alguns pontos de convergência entre este julgamento e a jurisprudência da Corte, a saber:

(a) O fornecimento de fármaco sem registro na Anvisa só é admitido na situação de excepcionalidade, em que sua utilização conta com aprovação de entidade congênere à agência reguladora nacional, e quando resta comprovado que é o único eficaz para debelar determinada enfermidade que coloca em risco a vida de paciente sem condições financeiras.

(b) A preocupação reiterada em diversos julgados ${ }^{30} \operatorname{com}$ a preservação do princípio da separação de poderes, rechaçando o que qualificou como interferência indevida do Poder Legislativo em função típica do Poder Executivo. Como visto, restou consignado da decisão plenária que uma lei - no caso, a Lei n. 13.269/2016-, ato do Poder Legislativo, não poderia substituir o registro, ato típico do Poder Executivo.

\footnotetext{
${ }^{28}$ São casos em que, muito embora os medicamentos requeridos não possuíssem registro na Anvisa, o fornecimento foi admitido, uma vez que adquiridos por intermédio de organismos multilaterais internacionais, para uso de programas em saúde pública pelo Ministério da Saúde, nos termos da Lei 9.782/99. Não se trata, portanto, de drogas em caráter experimental, sem que haja, ainda, pesquisas conclusivas sobre sua toxidade, eficácia e segurança. A título de exemplo, destacamos os seguintes julgados: STJ, AGRESP 201403175886, Segunda Turma, Rel. Min. DIVA MALERBI (DESEMBARGADORA CONVOCADA TRF $3^{\mathrm{a}}$ REGIÃO), j. 18/02/2006, DJe 26/02/2006; TRF1, AC 0026137-53.2011.4.01.3400, Quinta Turma, Rel.Juíza Federal DANIELE MARANHÃO COSTA, j. 28/09/2016, e-DJF1: 07/10/2016; TRF1, AG 0045384-64.2013.4.01.0000, Quinta Turma, Rel.DESEMBARGADOR FEDERAL NÉVITON GUEDES, j. 25/05/2016, e-DJF1: 13/09/2016; TRF3, Al 00063485320164030000, Terceira Turma, Rel. DESEMBARGADOR FEDERAL ANTONIO CEDENHO, j. 06/10/2016, e-DJF3 Judicial: 20/10/2016.

${ }^{29}$ Como, aliás, bem enfatizou Lewandowski em sua decisão nos autos da STA 828/SP. SUPREMO TRIBUNAL FEDERAL. Suspensão de Tutela Antecipada n. 828/SP, cit.

${ }^{30}$ Observem-se as seguintes decisões: STF, ADI 2225/SC, Tribunal Pleno, Relator: Min. DIAS TOFFOLI, j. 21/08/2014, DJe 29/10/2014; e STF, ADC 33/DF, Tribunal Pleno, Relator: Min. GILMAR MENDES, j. 18/06/2014, DJe 29/10/2014.
} 
(c) A prevalência da situação clínica individual do paciente, com base em laudo médico, sobre as regulamentações administrativas foi novamente relativizada, desta feita ponderando-se o risco advindo da utilização de uma droga cuja eficácia, segurança e toxidade ainda não haviam sido devidamente testadas.

(d) Em que pese a divergência dos ministros Edson Fachin, Rosa Weber e Dias Toffoli, que votaram pela possibilidade de permitir aos pacientes terminais o acesso ao medicamento, o plenário, por maioria, rejeitou esta possibilidade. Dessa forma, consolida mais uma vez a orientação já reiterada em vários julgados $^{31}$, no sentido de que o direito público subjetivo à saúde representa prerrogativa jurídica indisponível e indissociável do direito à vida.

\section{Referências}

ALVES, Sandra Mara Campos; DELDUQUE, Maria Célia; SANTOS, Alethele Oliveira. Lei no 13.269/2016: a comoção da sociedade vence o método científico! Cad. Saúde Pública, Rio de Janeiro, v. 32, n. 6, jun. 2016. Disponível em: <http://www.scielo.br/pdf/csp/v32n6/16784464-csp-32-06-e00070116.pdf>. Acesso em: 31 jan. 2017.

BALESTRA NETO, Otávio. A jurisprudência dos tribunais Superiores e o direito à saúde. Evolução rumo à racionalidade. R. Dir. Sanit., São Paulo v.16 n.1, p. 87-111, mar./ jun. 2015. Disponível em: <http://www.revistas.usp.br/rdisan/article/view/100025>. http://dx.doi.org/10.11606/issn.2316-9044.v16ilp87-111.

FERREIRA, Filipe Galvão et al. Fármacos: do desenvolvimento à retirada do mercado. Rev. Eletrônica de Farmácia, v. 6, n. 1, p. 14-24, 2009. Disponível em: <https://www.revistas.ufg.br/ REF/article/download/5857/4557>. Acesso em: 31 jan. 2017.

FREITAS, Letícia Figueira. Pesquisas envolvendo medicamentos na região Sudeste, Brasil: uma análise exploratória na base de dados do Sistema de Avaliação Ética de Pesquisas. 118f. 2011. Dissertação (Mestrado em Saúde Pública). Escola Nacional de Saúde Pública Sergio Arouca, Rio de Janeiro, 2011.

LENHARO, Mariana. 'Cápsula da USP' contra câncer não foi testada clinicamente; entenda, 2015. Disponível em: <http://g1.globo.com/ciencia-e-saude/noticia/2015/09/pilula-da-uspcontra-cancer-nao-passou-por-testes-clinicos-entenda.html>. Acesso em: 13 jul. 2016.

LIMA, Janderson et al. Pesquisa clínica: fundamentos, aspectos éticos e perspectivas. Revista da Socerj, v.16, n.4, p.225-233, 2003. Disponível em: <http://www.rbconline.org.br/artigo/ pesquisa-clinica-fundamentos-aspectos-eticos-e-perspectivas/>. Acesso em: 31 jan. 2017.

\footnotetext{
${ }^{31} \mathrm{~A}$ Corte já havia se manifestado nesse sentido em diversas oportunidades. A título ilustrativo, podemos indicar os seguintes julgados: STF, ARE 730741 / SP, Rel. Min. CELSO DE MELLO, j. 01/02/2013, DJe 20/03/2013; STF, RE 271286 Agr / RS, Rel. Min. CELSO DE MELLO, j. 12/09/2000, DJ: 24/11/2000, p. 0101; e STF, RE 273834 / RS, Rel. Min. CELSO DE MELLO, j. 23/08/2000, DJ: 18/09/2000, p. 0037.
} 
PIMENTEL, Luis Cláudio Ferreira et al. O inacreditável emprego de produtos químicos perigosos no passado. Química Nova, v. 29, n. 5, p. 1138-1149, 2006.

PIVETA, Marcos. A prova final da fosfoetanolamina, 2016. Revista Pesquisa FAPESP, ed. 243, maio 2016. Disponível em: <http://revistapesquisa.fapesp.br/2016/05/17/a-prova-final-dafosfoetanolamina/>. Acesso em:13 jul. 2016.

STF suspende eficácia da lei que autoriza uso da fosfoetanolamina. Portal do STF, 19 maio 2016. Disponível em: $<$ http://www.stf.jus.br/portal/cms/verNoticiaDetalhe.asp?idConteudo=317011 \&caixaBusca=N>. Acesso em: 13 jul. 2016.

VENTURA, Miriam. O processo decisório judicial e a assessoria técnica: a argumentação jurídica e médico-sanitária na garantia do direito à assistência terapêutica no SUS.186f. 2012. Tese (Doutorado em Saúde Pública). Escola Nacional de Saúde Pública Sergio Arouca, Rio de Janeiro, 2012.

José Carlos Zebulum - Doutorando em Saúde Pública pela Universidade Federal do Rio de Janeiro; mestre em Direito pela Universidade do Estado do Rio de Janeiro; graduado em Engenharia Naval pela Universidade de São Paulo. Professor da Fundação Educacional Serra dos Órgãos e Magistrado. Rio de Janeiro/RJ, Brasil. E-mail: jcarloszebulum@gmail.com. 